\title{
A Geopolítica da Amazônia no século XXI: o pensamento de Mário Travassos revisitado
}

\section{The Geopolitics of Amazon in the $21^{\text {st }}$ Century: revisiting Mario Travasso's reflections}

Rev. Bras. Est. Def. v. 5, nº 1, jan./jun. 2018, p. 87-114

DOI: 10.26792/RBED.v5n1.2018.75091

ISSN 2358-3932

ANDRÉ LUIZ VARELLA NEVES

\section{INTRODUÇÃO: A GEOPOLÍTICA DO BRASIL E VISÃO PANORÂMICA DA PRODUÇÃO ACADÊMICA}

O Brasil foi um dos primeiros países na América do Sul a produzir estudos sobre geopolítica stricto sensu, pois as teorias originárias de Ratzel e Kjellén encontraram terreno fértil em nosso país. Isto ficou evidenciado devido à repercussão, no Brasil, da célebre Conferência de Mackinder, intitulada The Geographical Pivot of History na Real Sociedade Geográfica de Londres em 1904, complementada pelo artigo Democratic Ideals and Reality, publicado no Foreign Affairs, em 1919. Assim, surgia no Brasil um estudo preocupado com o papel da geografia na formulação da política nacional através de Elyseo de Carvalho, denominado de Factor Geográfico na política brasileira, de 1921.

A gênese da produção geopolítica no nosso país ocorreu nas décadas de 20 e 30, dando início a uma produção bibliográfica extremamente profunda, tanto quantitativamente como qualitativamente. Ao contrário do que é corrente se pensar, estes trabalhos são praticamente desconhecidos no meio acadêmico, e, segundo Miyamoto, nutre-se em relação a eles um preconceito que perdura desde a década de 1940, o que é demonstrado pela ausência de cientistas políticos na elaboração e análise geopolíticas (Miyamoto 1981, 76).

Além de Elyseo de Carvalho, surgiram neste período outros autores como Everardo Backheuser, Carlos Delgado de Carvalho, Mário Travassos e Francisco de Paula Cidade, cujos trabalhos demonstraram a influência do pensamento de Ratzel.

André Luiz Varella Neves - Doutor em Ciência Política pela FFLCH. Programa de Pós Graduação do Departamento de Ciência Política da Universidade de São Paulo (USP). 
Para a literatura especializada, a grande figura da geopolítica nacional foi Everardo Backheuser, pelo pioneirismo da sistematização de informações desordenadas sobre o país. Foi com este autor que o estudo da geopolítica no Brasil foi impulsionado, pois a sua profícua produção, inaugurada com a obra Pela Unidade do Brasil, em 1925, iria continuar ao longo das três décadas que se seguiram. Suas considerações versavam desde uma teoria sobre a possível marcha da civilização e discussões teóricas sobre geopolítica e geografia política, até a mudança da Capital Federal.

A década de 40 apresentou-se fértil e a que mais produziu estudos sobre geopolítica, e, apesar disso, a qualidade dos trabalhos não superou as obras de Travassos e Backheuser. São desse período as obras de Lima Figueiredo, Leopoldo Nery da Fonseca, Lysias Rodrigues, Djalma Poli Correa, Carlos Delgado de Carvalho, Raja Gabaglia e Moisés Gikovate.

Os anos 1950, com o advento da Escola Superior de Guerra no final da Segunda Guerra Mundial, marcaram uma nova etapa nos estudos geopolíticos com o surgimento de uma nova geração de estudiosos, a saber: Therezinha de Castro, Meira Mattos, Golbery do Couto e Silva, João B. Magalhães, Waldyr Godolphim e Lyra Tavares.

As décadas de 1960 e 1970 assinalaram um período em que as preocupações estiveram voltadas para a segurança nacional e o fortalecimento do poder nacional. Encontra-se neste período, a publicação da obra Projeção Mundial do Brasil, do General Meira Matos, na qual, logo na introdução, o autor pede licença para sonhar não mais como um país de projeção continental, fazendo alusão a obra de Mário Travassos, mas antes, com um país de projeção internacional. Buscou mostrar por que o país deveria assumir um papel de relevo no concerto mundial de nações, sendo esta a tônica que guiará todos os seus ensaios posteriores (Miyamoto 1981, 80-82).

Feito este sumaríssimo balanço da produção geopolítica brasileira desde os seus primórdios, o objeto deste artigo é a tese proposta por Mário Travassos no trabalho considerado de fundamental importância para a compreensão da geopolítica brasileira publicado em 1931. Trata-se de Aspectos Geográficos sul-americanos, reeditado em 1947 com o título de Projeção Continental do Brasil (Mello 1997, 55).

Estas ideias, expostas há 87 anos, propiciam o distanciamento e a perspectiva necessária e suficiente para um imprescindível ajuste de contas com o autor. Podemos considerá-lo como o pai fundador da Geopolítica brasileira, pois lançou os fundamentos para a Geopolítica do Brasil na primeira metade do século XX.

Neste sentido, o nosso interesse é verificar quais foram as instabilidades geográficas percebidas por Travassos na região noroeste da América do 
Sul, compreendendo os países como a Bolívia, a Colômbia e o Equador, e as inquietações políticas que delas derivaram.

O objetivo é resgatar a reflexão do autor àquelas contribuições teóricas no que tange às influências americanas advindas do Canal do Panamá, submetendo-as ao crivo das mudanças da política internacional na América do Sul.

\section{ASPECTOS CAPITAIS DA GEOGRAFIA SUL-AMERICANA}

Os postulados essenciais da teoria de Travassos para a compreensão do complexo geopolítico da América do Sul estão no entendimento de que os Estados buscam contar com várias saídas para o mar, se possível para mares diferentes, e aspiram também ao domínio da totalidade das bacias hidrográficas que estiverem ao seu alcance. Para o autor, qualquer potência que disponha de seções navegáveis de um grande rio tenderá a estender este domínio até sua foz e, do mesmo modo, inversamente, quando uma potência dominar a boca de um caudal tenderá expandir-se até as cabeceiras.

Fazendo a alusão à América do Sul, e sob o crivo dos fatos históricos, geográficos e estratégicos do Império Alemão, da Rússia e da Inglaterra, ${ }^{1}$ nota-se que estes exemplos permitem-nos estimar consequências mediatas e imediatas pela presença do antagonismo entre os oceanos Pacífico e Atlântico. Eles também nos ajudam diagnosticar a complexidade dos problemas oriundos das múltiplas regiões hidrográficas da região, revelados desde a colonização e mantidos em estado latente após a formação dos Estados sul-americanos. A gravidade destas questões está relacionada ao fato de que cada uma das regiões hidrográficas abriga mais de uma soberania, suscitando a possibilidade do surgimento de conflitos que poderiam alterar o mapa político na América do Sul.

Segundo o autor:

São tais as circunstâncias, apresentam tal gravidade, que há quem faça o prognóstico de profundas modificações, ainda no mapa político da América do Sul principalmente pelo fato de cada uma de suas grandes bacias encontrar-se sob a bandeira de mais de um Estado - a do Orinoco, repartida entre a Venezuela e a Colômbia; a do Amazonas, com sua prodigiosa rede de afluentes, entre o Brasil, a Colômbia, o Equador, o Peru e a Bolívia; a do Uruguai, entre o Brasil, a Argentina e o Uruguai; a do Paraguai, entre o Brasil, a Bolívia, o Paraguai e a Argentina; a do Paraná, entre o Brasil, o Paraguai e a Argentina (Travassos 1947, 17, grifos nossos).

Sendo assim, a obra Aspectos Geográficos Sul-americanos deve ser entendida à luz dos postulados acima, num ensaio em que são analisados 
os aspectos geográficos e o peso dos mesmos como fenômenos condicionantes dos processos políticos e econômicos de profunda repercussão continental.

Nesse trabalho, o autor estudou a situação geopolítica do Brasil na América do Sul apoiando-se em três ideias estruturantes: a) o enquadramento da massa continental por dois oceanos diferentes, a leste, o Oceano Atlântico e a oeste, o Oceano Pacífico; b) a oposição sistematizada entre duas bacias hidrográficas do continente, ambas na vertente atlântica - a do Amazonas ao norte e a do Prata no sul; e c) a existência de países mediterrâneos, o caso da Bolívia e do Paraguai, justo na região em que aqueles antagonismos se encontram.

Em outras palavras, quaisquer considerações sobre os processos políticos e econômicos que se desenrolam na América do Sul devem ter como premissa a constatação que se enquadram entre dois grandes antagonismos geográficos: Atlântico x Pacífico e a Bacia Amazonas x a Bacia do Prata.

O primeiro antagonismo geográfico é caracterizado pela oposição entre os dois oceanos que envolvem a massa sul-americana, cortada na direção longitudinal pela espinha dorsal da Cordilheira dos Andes, cujo cume divide desigualmente as vertentes continentais. $O$ Atlântico desempenhava o papel de polo dominante como eixo da civilização ocidental, sendo a via de comunicação por excelência entre o Novo e o Velho Mundo. O Pacífico, com seu litoral inóspito, era o "mar solitário" situado à margem dos grandes feixes de comunicações marítimas e via de contato intermitente com a Ásia oriental. O segundo antagonismo resultava da oposição entre esses dois grandes sistemas fluviais - o Amazonas e o Prata - e que, dada a proximidade dos Andes da costa pacífica e o divortium aquarium ${ }^{2}$ formado pelo altiplano boliviano, corriam ambos para o leste, mas em direções opostas, desaguando um ao norte e outro ao sul da vertente atlântica. Esse antagonismo se expressava no conflito entre ambas as bacias, cujas desembocaduras, controladas pelo Brasil e pela Argentina, buscavam conquistar a posição de principal via de comunicação da vertente pacífica com a vertente atlântica, obtendo através dessa o acesso à "civilização mundial" (Travassos 1947, 71-72, grifos nossos). 


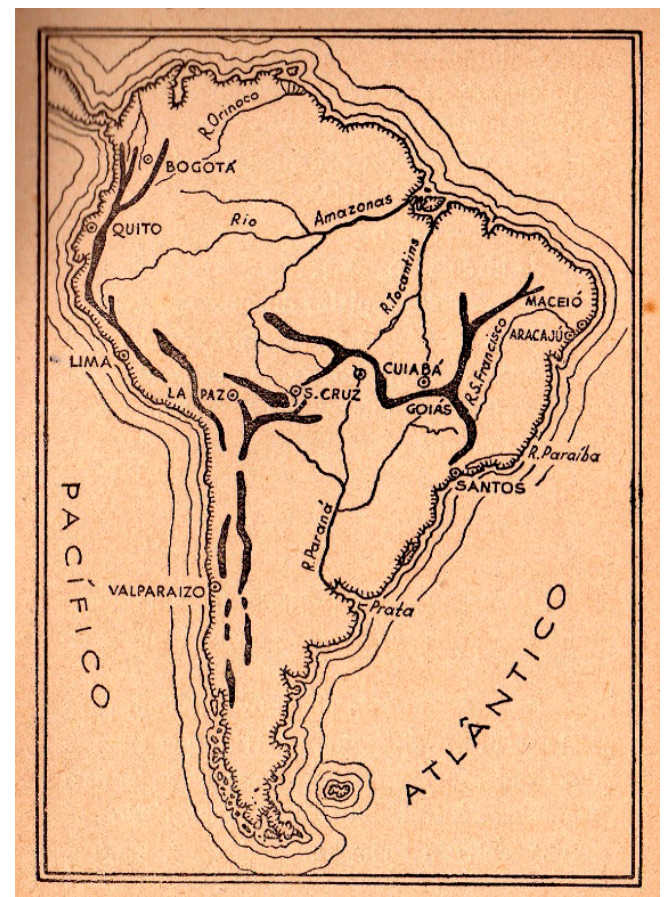

Mapa 1 - Antagonismo geográfico.

Fonte: Travassos $(1947,45)$.

\section{PROJEÇÃO PLATINA: O TEMOR DE TRAVASSOS}

O motivo da sua preocupação naquele momento era o caráter expansionista da política de comunicação platina que se projetava através da sua rede ferroviária estabelecendo contato entre Buenos Aires e as capitais de três países limítrofes: Assunção, Santiago e La Paz.

A sua atenção dirigia-se principalmente para a região em que o sistema de comunicação platino estabelecia a ligação entre Buenos Aires e La Paz. Este fato resultava em implicações geopolíticas importantes pois permitia que através de La Paz, os trilhos argentinos alcançassem os portos do Chile, como Antofagasta, Mejillones e Arica e também ao porto de Mollendo, no Peru.

Esta situação permitiria à Argentina alcançar uma preponderância geopolítica na região, e por conta disso Travassos concluiu que era essencial para o Brasil barrá-los neste esforço de projeção continental.

Inspirado pelas concepções teóricas de Mackinder sobre a Eurásia, o heartland e o poder terrestre, Travassos formulou que a chave para a re- 
solução dos dois grandes antagonismos, Atlântico x Pacífico e a Bacia do Amazonas e a Bacia do Prata, encontrava-se no planalto boliviano. Por sua localização geográfica e estratégica no centro do continente, era considerado o heartland sul-americano, sendo este o ponto central que constitui o cerne da sua teoria geopolítica.

Segundo o autor,

O território boliviano pode ser considerado o centro geográfico do continente sul-americano, $[\ldots]$ como fonte orográfica abrindo o sistema andino, simultaneamente, às influências político-econômicas que as bacias do Amazonas e do Prata representam na massa continental. Ao passo que o planalto é procurado instantaneamente pelas comunicações chilenas, peruanas e argentinas, é o planalto boliviano que procura escapar às tenazes dessa submissão por meio das comunicações brasileiras (Travassos 1947, 232).

Sendo assim, para conter o avanço da Argentina para o centro do continente, percebeu que seria vital o controle do triângulo estratégico para a resolução dos antagonismos entre a Bacia Amazônica e a Bacia do Prata a favor do Brasil.

Para enfrentar esta situação, Travassos encarava como imperativo geopolítico vital o deslocamento do centro de gravidade do triângulo estratégico da cidade de Cochabamba para a cidade de Santa Cruz de La Sierra. Como esta fazia fronteira com o Brasil, o autor defendia a construção de uma ferrovia que ligasse a cidade aos rios Madeira e Mamoré. Estes, por sua vez, serviriam de conexão fluvial entre o triangulo boliviano e a bacia amazônica.

O objetivo a ser atingido com a transferência do eixo gravitacional de Cochabamba para Santa Cruz de La Sierra seria alcançar o controle do triângulo estratégico, o que significaria a neutralização do sistema ferroviário platino e a Bacia do Prata. Desta forma, colocaria o altiplano boliviano sob a influência carreadora da bacia Amazônica, assegurando ao Brasil a posição de país geopoliticamente hegemônico no heartland sul-americano (Mello 1997, 66).

Segundo Travassos :

[...] do exposto trata apenas de deslocar o centro de atração da região de Cochabamba para Santa Cruz, porque a atração exercida por Cochabamba é, por assim dizer, artificial, produto das facilidades de comunicações de que tem desfrutado, ao passo que Santa Cruz representa realmente o verdadeiro centro de gravidade da economia do planalto [...] (Travassos 1947, 65). 
Uma vez assegurada as comunicações pelo Amazonas, o passo seguinte era estabelecer a conexão da Bacia Amazônica com a Cordilheira dos Andes, com o objetivo de canalizar para o Atlântico a produção dos países andinos situados na vertente oriental do continente sul-americano. Esta conexão iria ocorrer pelos $n u d o s,{ }^{3}$ localizados em três países andinos: o de Pasto, na Colômbia, o de Loja, no Equador e os de Pasco e Cusco, no Peru.

Para responder a este desafio, o autor parte de uma análise da massa territorial do país, a fim de verificar o seu papel em relação ao conjunto do continente sul-americano, delimitando o território brasileiro por dois tipos de condicionantes: um geográfico e outro político. Divide desta maneira o país em quatro regiões naturais: Brasil Amazônico, Nordeste Subequatorial, a Vertente Oriental dos Planaltos e o Brasil Platino (Mello 1997, 61-76).

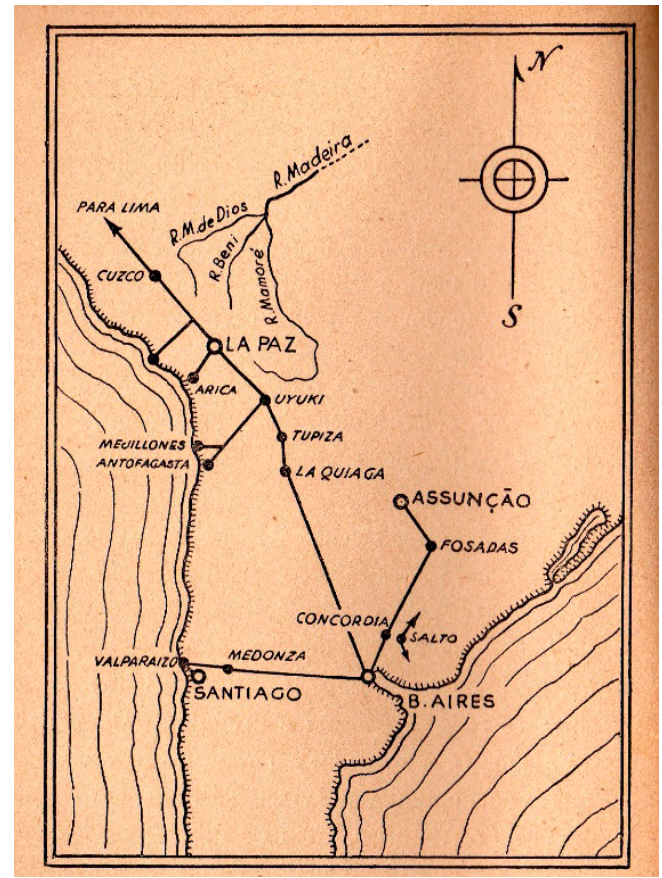

Mapa 2 - Esforço Ferroviário Platino.

Fonte: Travassos (1947, 54).

Segundo Travassos (1947, 127-128):

O Brasil amazônico, comportando a região serrana (maciço granítico das Guianas), a depressão amazônica (calhas do Amazonas e seus afluentes) e a Hileia (região das matas); o Nordeste subequatorial, abran- 
gendo o Golfão Maranhense (sorte de transição da Amazônia), a bacia do Paraíba, as Serras e Chapadas da Vertente Norte-Oriental (regiões semiáridas), o litoral, a mata e o agreste de Pernambuco (balizada pelo Cabo de São Roque, foz do São Francisco e Serra da Borborema); a Vertente Oriental dos Planaltos, compreendendo o litoral baiano-espírito-santense (inclusive as bacias do Paraguaçú, Jequitinhonha e Doce) e região das chapadas (zona alta), o vale do São Francisco, o sul Mineiro e o vale do Paraíba; o Brasil Platino, englobando a costa ou contra-vertente oceânica (entre o Atlântico e a Serra do Mar), a Região Serrana (Serra do Mar e Geral), a região do Planalto (alternação de campos e matas, região suporte dos afluentes orientais do Paraná), a campanha rio-grandense e a baixa mato-grossense - em seu conjunto, nada mais espontâneo que essas grandes divisões e respectivas subdivisões.

Analisando o papel funcional destas regiões, constata-se a existência de dois Brasis: o Amazônico e o Platino. Percebe-se que, a partir de pontos extremos da vertente atlântica, convergem ambos para o centro geográfico do continente onde está localizado o heartland boliviano. Em seguida verifica que as duas outras regiões - Vertente Oriental dos Planaltos e o Nordeste Subequatorial - são prolongamento uma da outra e formam o que Travassos denominou de "Brasil Longitudinal", que teria um papel funcional de estabelecer a ligação entre as duas primeiras regiões: Brasil Amazônico e o Brasil Platino.

Comentando sobre estes aspectos, escreve Travassos (1947, 129-130):

O Brasil amazônico se comunica de modo mais direto com o oceano, por isso que dispõe do Rio Amazonas como via natural. E sua capacidade de penetração é mais ampla, pois o vale amazônico é o grande coletor do formidável anfiteatro que se arqueia de Caracas a La Paz. O Brasil Platino, apesar de que exija meios artificiais para ligar-se ao oceano, dispõe de portos com suficiente capacidade de atração na costa e dos estímulos de dois países mediterrâneos que naturalmente reagem contra a força centrípeta do Prata: o sul de Mato Grosso, prolongando os territórios paulista e paranaense, representa a sua força de penetração. [...] Em segundo lugar há que considerar as outras duas regiões naturais, a Vertente Oriental dos Planaltos e o Norte Subequatorial-que se prolongam de modo a justificar o título que lhe atribuímos de Brasil Longitudinal (grifos nossos). 


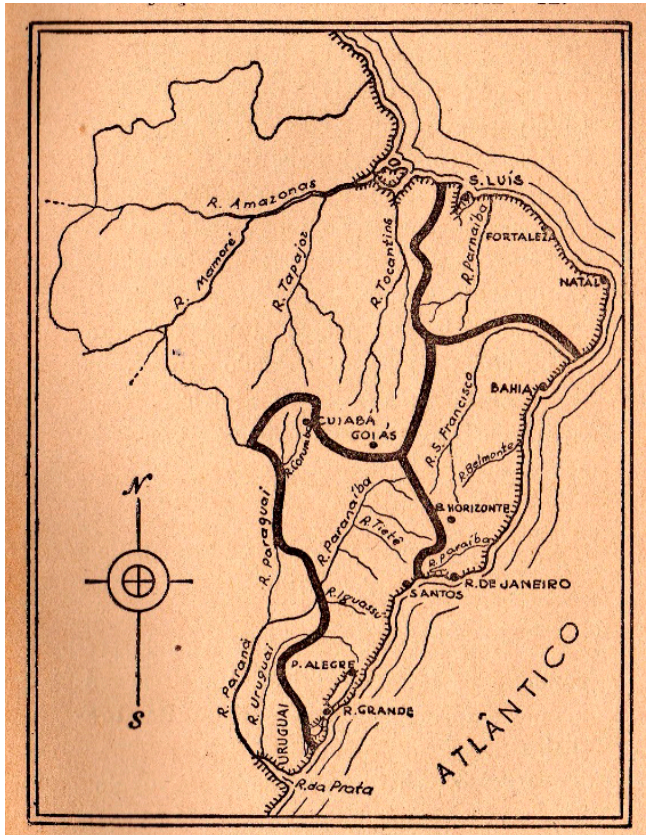

Mapa 3 - Regiões Naturais.

Fonte: Travassos $(1947,127)$.

O autor chega à seguinte conclusão, extraída dessa síntese geográfica: a de que a consolidação da unidade do país dependeria da conjuração de dois tipos de atuação:

É mais que certo repousar a sua mantença nessas duas ordens de fenômenos: atuações convergentes do Brasil Platino e Amazônico sobre o centro geográfico do continente considerado objetivo comum; esforços de unir as duas extremidades $[\ldots]$ que denominamos $[\ldots]$ de Brasil Longitudinal (Travassos 1947, 193, grifos nossos).

\section{Política de Comunicações}

Isto posto, a proposta de Travassos era o desenvolvimento e implementação de uma ousada política de comunicações, a qual seria construída através de um sistema misto baseado na pluralidade de transportes (ferroviário, rodoviário, hidroviário, marítimo e aéreo), que tinha dois grandes objetivos: garantir deste modo a unidade territorial do país e a articulação de suas diversas regiões, e assegurar a projeção política e econômica do Brasil no continente sul-americano (Mello 1997, 84). 
Esta política de comunicações visava:

a) Drenagem de grande parte das riquezas da vertente ocidental para a vertente oriental do continente sul-americano, conectando pelos $n u$ dos andinos com o transporte fluvial pela Bacia Amazônica;

b)Em relação ao antagonismo da Bacia hidrográfica do Amazonas e a Bacia do Prata, o alvo seria o controle do triângulo estratégico boliviano e do heartland continental. A chave seria o domínio do vértice representado pela cidade de Santa Cruz de La Sierra, que seria conectada por via ferroviária tanto ao Porto de Santos quando ao Madeira Mamoré que, por sua vez, serviria de ligação fluvial com a Bacia Amazônica;

c) Quanto à neutralização da Bacia do Prata e da Rede Ferroviária argentina, a ação a ser implementada era o estabelecimento de um sistema de comunicações transversais, por via ferroviária e rodoviária, realizando assim a ligação entre os países mediterrâneos e os portos brasileiros no Atlântico;

d)Estabelecer a ligação do Brasil Platino e do Brasil Amazônico com o Brasil longitudinal por meio da justaposição e da combinação de transporte marítimos, fluviais e terrestres.

\section{Elite brasileira: sem visão e sem ação}

O autor identificava que os problemas nas comunicações no Brasil estavam na falta de uma elite esclarecida que tivesse uma visão de conjunto para enxergar os problemas em toda sua ampla envergadura.

Num país de formação tumultuária e de complexidade territorial, e pela ausência de um plano de ação, temos como consequência "sido obrigados a resolver questões premidos por injunções de toda a sorte, assim no tempo como no espaço, e arcando com a incipiência de nossas próprias possibilidades" (Travassos 1947, 193).

$\mathrm{O}$ autor enxergava que a questão das comunicações brasileiras estava acima do complexo dos demais problemas que impediam o aproveitamento das possibilidades do país e adverte que:

Isto de querer, por exemplo, primeiro ceifar o analfabetismo para chegar às verdades das urnas e, em seguida, investir contra o resto, ou realizar a verdade eleitoral para depois partir seguramente para a solução das questões, ou de qualquer outra forma de precedência, não passa de simples fantasia, apesar de acalentada por muitos espíritos votados à grandeza nacional. Puro simplismo. [...] Inegável que o problema das comunicações sobreleva no complexo dos demais problemas (Travassos 1947, 195). 
Diz o autor que o nosso erro de origem estava em não termos consultados nossas características geográficas em busca de uma visão de conjunto sobre as grandes linhas de circulação naturais. Por conta disso, ocorreu uma versatilidade em matéria de comunicações, em que recaíram preferências sobre certos tipos de transportes em detrimento de outros, conduzindo-nos "às direções falsas, às confusões sobre a verdadeira finalidade das linhas - se nacionais, se regionais -, enfim, todo o acervo das impropriedades que se podem constatar no que já possuímos quanto a comunicações (Travassos 1947, 198).

Travassos comenta que se os dirigentes brasileiros tivessem formulado um documento de base, o desenvolvimento de nossas comunicações não se teria processado ao sabor dos acontecimentos, e

nunca chegaríamos aos extremos que se verificam com a astenia de certas regiões assaz promissoras e a descontinuidade de comunicações terrestres em que ainda se encontra o território nacional. Por conta disso, diz o autor, [...] é que ainda não possuímos as grandes artérias nacionais [...] de caráter econômico, estratégico ou político, esquecidos de que sem essas vias estarem ligadas a uma trama integral de comunicações, adquirem significado absolutamente ilusório (Travassos 1947, 201, grifos nossos).

A função das comunicações tem papel decisivo na manutenção dos Estados e, no caso brasileiro, assume notável gravidade, por que muito deixam a desejar como sistemas de forças a um tempo políticas, sociais e econômicas.

Ao fim e ao cabo, as grandes diretrizes geopolíticas de Mário Travassos para a consecução da preponderância política e econômica do Brasil na região seriam o estabelecimento de uma ousada política de comunicações para a) alcançar a supremacia da vertente atlântica e da Bacia Amazônica; b) controlar o heartland continental, ou seja, o triângulo estratégico boliviano; e c) neutralizar a Bacia do Prata e a influência sobre os países mediterrâneos; e, por último, d) investir o fortalecimento do Brasil longitudinal para obter a projeção continental do país.

\section{AMÉRICA DO SUL: INSTABILIDADE GEOGRÁFICA E INQUIETAÇÃO POLÍTICA}

Após a análise dos aspectos capitais da geografia sul-americana e o papel do Brasil na região, o autor passa examinar o que denominou os signos de inquietação política existente no continente da América do Sul. Estas perturbações são provenientes das instabilidades geográficas, ou seja, da oscilação 
de certos territórios em determinadas circunstâncias. Segundo Travassos, os "territórios assim oscilantes são verdadeiros focos de perturbações políticas, causas de dissensões ou, pelo menos, de preocupações sérias para que se evitem possíveis conflitos internacionais" (Travassos 1947, 81).

O autor aborda os casos da Bolívia, da Colômbia e o Uruguai, entretanto o nosso interesse é discutir os dois primeiros casos e as influências exteriores vindas do Canal do Panamá.

Em relação à Bolívia, os fatores determinantes da sua instabilidade geográfica e que repercutem em suas preocupações políticas está na sua condição de país mediterrâneo, resultante da amputação da sua costa pela Guerra do Pacífico. Aqui, para Travassos, encontram-se as verdadeiras causas da sua instabilidade política, pois de um lado está "sua vinculação geológica à estrutura andina e, de outro, a sua oscilação diante das bacias que lhe corroem os flancos - a Amazônica e a Platina" (Travassos 1947, 82).

Em outras palavras, a Bolívia sofre diretamente os efeitos das discordâncias entre o Chile e o Peru, e a oscilação pendular entre os dois polos de atração, a Bacia Amazônica e a Bacia do Prata, ambas representadas respectivamente por Brasil e Argentina, sendo que este último era, naquele momento, o grande beneficiário da instabilidade da Bolívia, uma vez que se encontrava dependente do porto de Buenos Aires para escoar sua produção, cujo transporte se realizava via fluvial através da Bacia do Prata ou, por via terrestre, através da via férrea argentina.

Para Travassos, o Brasil deveria intervir a fim de pender a dependência da Bolívia em favor de nosso país, criando, para isso, alternativas de tráfego fluvial pela Bacia Amazônica e de transporte terrestre até o Porto de Santos, cuja ligação com Corumbá, pela Ferrovia Noroeste, poderia ser prolongada até a cidade de Santa Cruz de La Sierra.

As instabilidades políticas da Bolívia poderiam ter importantes repercussões no continente, conforme afirma o autor:

E de todo este exame pode-se fixar de modo categórico o sentido político da Bolívia como centro geográfico do continente e a causa eventual de conflito armado, cujo vulto poderá mesmo assumir o caráter de verdadeira conflagração (Travassos 1947, 84-90).

A oscilação entre as forças político-econômicas que as bacias do Amazonas e do Prata representam, essa sim pode traduzir verdadeiro motivo de apreensões internacionais mais sérias. Essas bacias significam interesses de toda sorte, ligados às duas mais importantes nações do continente, que, se tudo as une, nem por isso estão de todo livres de possíveis estremecimentos provindos do planalto central do continente (Travassos 1947, 84-90). 


\section{Equador - Colômbia - Venezuela e Canal do Panamá}

No noroeste da América do Sul, na região compreendida pelos territórios do Equador, da Colômbia e da Venezuela, que "do ponto de vista geológico, certos autores designam por um triângulo cujos vértices se apoiam no Golfo de Guayaquil, no de Darien e na Ilha da Trindade, detecta-se uma segunda instabilidade geográfica”. (Travassos 1947, 84).

Ela ocorre devido ao fato de essa extremidade do continente estar refém das influências políticas e econômicas vindas do Mar das Antilhas, e do grande polo de atração que representa o Canal do Panamá.

Segundo o autor:

Atualmente, porém, sua importância desperta novos influxos. As influências políticas e os interesses econômicos que se aninham no Mar das Antilhas e o foco de atração que o Canal do Panamá representa são, por si sós, capazes de sublinhar suficientemente a instabilidade geográfica dessa extremidade continental, erigindo aí, como no centro do mesmo continente, outro caso de fragilidade política (Travassos 1947, 85).

Analisando o mapa da América do Sul, Travassos verificou que "o conjunto da região é trabalhado simultaneamente por duas influências marítimas diferentes, senão opostas - a do Pacífico e a do Atlântico" (Travassos 1947, 86).

O Pacífico, exercendo influência sobre o Golfo de Guayaquil, no Equador, encontra toda a força da dinâmica fluvial da vertente atlântica expressa pelo Rio Atrato e a extensão penetrante dos Rio Madalena e do Cauca, na Colômbia. A repercussão destes caudais é “ $[\ldots .$.$] expressa pela$ navegabilidade do Orinoco e a concordância do Putumayo com o Solimões e o Amazonas, das mais extensas vias fluviais navegáveis [...]” (Travassos 1947, 87).

Diante desta análise geográfica, Travassos percebe a seguinte instabilidade geográfica: da mesma maneira que o território boliviano, que estando preso a estrutura andina, oscila entre as atrações da Amazônia e do Prata, o território colombiano, preso à Cordilheira dos Andes pelo nudo de Pasco, oscila entre as atrações de dois oceanos. Do lado do Pacífico encontra-se a Baía do Panamá, em que deságua o Canal; do lado do Atlântico estão três polos de atração formados pelos rios Madalena, Orinoco e o Amazonas (Travassos 1947, 88). 


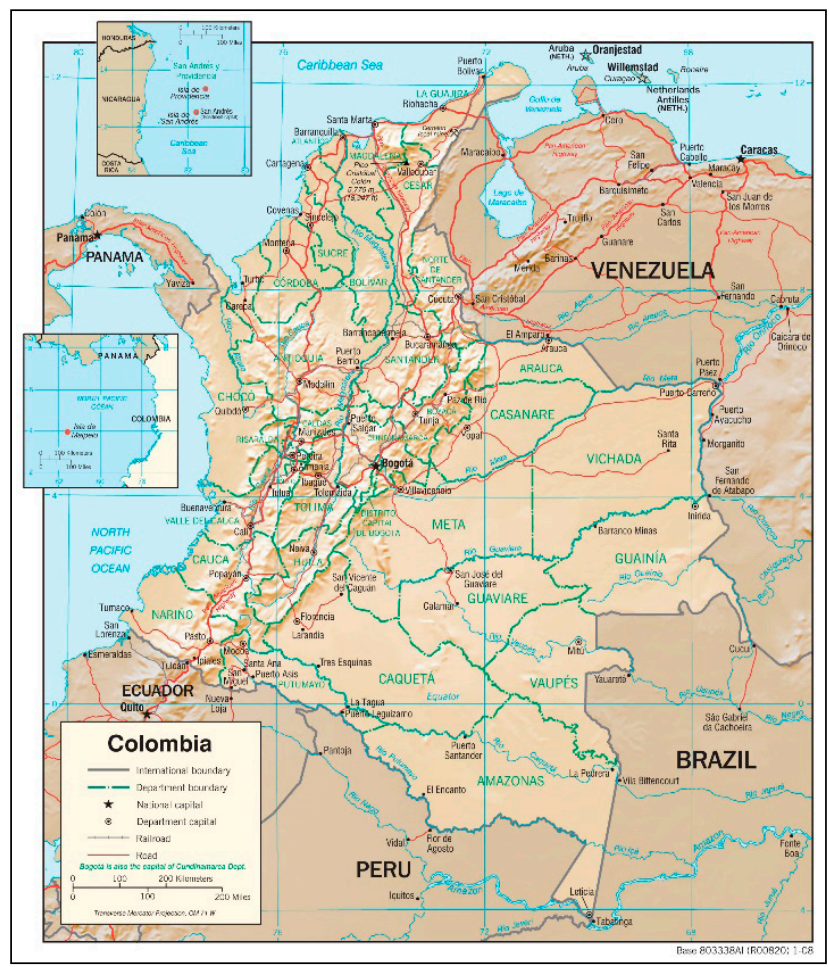

Mapa 4- Noroeste Sul-americano.

Fonte: Central Intelligence Agency (2017).

A questão que o preocupava era a seguinte: se a instabilidade geográfica do território boliviano apresenta consequências políticas de aspectos continentais, o mesmo não ocorre na região noroeste do continente sul-americano. Isto se dá pelo fato de que esta área estar localizada numa das extremidades da massa continental, mostrando-se, por conta disso, presa fácil de influências extracontinentais, ou seja, norte-americanas.

Em síntese, a inquietação política que repercute nesta região ocorre por estar na extremidade contígua a um dos mais intensos focos de influências sobre o continente sul-americano: o Canal do Panamá.

Para Travassos:

O Canal do Panamá - verdadeiro carrefour internacional - e o Mar das Antilhas - incubadora da influência ianque - exprimem bem o caráter das pressões que se exercem nessa extremidade do continente sul-americano. As linhas naturais de penetração que os vales do Madelena e do Orinoco representam dizem o resto (Travassos 1947, 91). 


\section{EUA e Canal do Panamá}

Para Travassos, o Canal do Panamá era entendido como o epicentro de todas as atuações políticas que visam a atender aos imperativos industriais americanos, dirigindo-se os seus interesses para a América do Sul.

As linhas de penetração norte-americanas vindo do Mar das Antilhas tinha como entrada na América do Sul as bacias do Orinoco e do Madalena. Funcionando como verdadeiros portais, permitiam que houvesse o contato direto com o vale do Amazonas, e indiretamente, com os nudos e as abertas andinas, facilitando, desta forma, a aproximação com a Bacia do Prata.

Travassos também notou que estes esforços ignoraram as Guianas, apesar de elas formarem um trampolim para saltar na Amazônia. Entretanto, concluiu que esta ação naquele espaço territorial foi evitada pois acarretaria difíceis questões políticas com a Europa (Travassos 1947, 114).

Os imperativos industriais referidos acima estavam relacionados às indústrias automobilística e aeronáutica, as quais buscavam na região dois produtos importantes: a borracha e o petróleo. Ou seja, estas ações correspondiam ao controle exercido pelos Estados Unidos sobre o petróleo da Venezuela, da Colômbia e do Peru e a atuação da Companhia Ford Industrial do Brasil na Amazônia.

Segundo ao autor:

Dada a importância avassaladoramente crescente do avião e do automóvel, sem dúvida nenhuma cabem à borracha e ao petróleo as referências que devem balizar o primeiro lanço às influências político-econômicas ianques em território sul-americano (Travassos 1947, 115, grifos nossos).

O autor destacou que, por causa das investidas norte-americanas na região, tanto o Equador como a Bolívia resolveram ratificar, por meio de legislação, a nacionalização do petróleo. Desta maneira, buscaram impedir o avanço sobre os seus recursos naturais estratégicos (Travassos 1947, 115). 


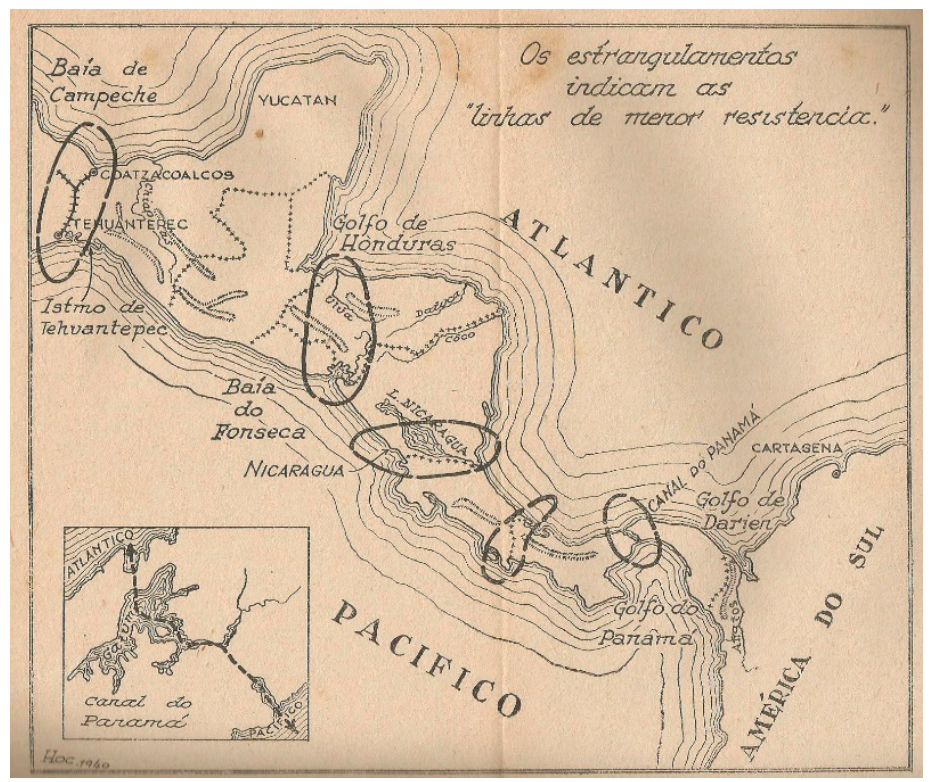

Mapa 5 - Canal do Panamá.

Fonte: Travassos $(1942,29)$.

\section{Prognóstico \& Preocupação de Travassos}

A hipótese travassiana ressaltou que o progresso da infiltração dos interesses norte- americanos ocorreria pelas vias andinas e pela costa do Pacífico, e sustentou esta afirmação por conta das facilidades fisiográficas da região e pelo fracionamento político do noroeste da América do Sul:

Embora não seja fácil prognosticar, tudo faz crer que os maiores progressos da infiltração dos interesses norte-americanos em nosso continente se farão pelas vias andinas e ao longo da costa do Pacífico. Corroboram com o nosso prognóstico, além das facilidades fisiográficas, o fracionamento político do território. Além disso é o meio mais seguro e o caminho mais direto para ir das Antilhas ao planalto boliviano, verdadeiro centro geográfico do continente do sul (Travassos 1947, 116, grifos nossos).

Segundo o autor, é desta maneira que as influências ianques irão atingir o território sul-americano, causando o que ele denominou, como comentamos anteriormente, os signos de inquietação política. Em relação ao Brasil, fez um alerta às elites nacionais, afirmando que, para nós, caberá o papel de exercer uma liderança, por conta das características geográficas, a fim 
de contrapor estas circunstâncias políticas e econômicas causadas pela presença norte-americana. Segundo Travassos (1947, 117), "Devemos lembrar-nos do papel coordenador que o Brasil é chamado a exercer - por sua posição e mais características geográficas - sobre tão complexas circunstâncias econômicas e políticas a envolverem o continente sul-americano em suas malhas".

\section{SÉCULO XXI - AMÉRICA DO SUL: NOVO CENÁRIO E MESMAS INQUIETAÇÕES}

O esforço de infiltração dos EUA na região da América do Sul na década de 30 será intensificado com a eclosão da Segunda Guerra Mundial. Os motivos serão os mesmos, ou seja, acesso aos recursos naturais, agora para atender as exigências da indústria bélica.

Em relação ao Brasil, a sua importância geopolítica, além de fornecedor de matérias-primas, recaía no fato de possuir um grande espaço territorial - no seu extenso litoral, faceando o Atlântico Sul, e no interior do continente, fazendo fronteiras com a maioria dos países da América do Sul, exceto Chile e Equador.

Naquele período, os EUA receavam que um avanço das forças alemãs, a partir da costa do Senegal, alcançasse as Américas através do estreito Natal-Dakar e se estabelecessem no arquipélago de Fernando de Noronha, e que partir daí ocupassem o saliente nordestino, que engloba Rio Grande do Norte, Paraíba, Pernambuco e Alagoas. Esta preocupação foi demonstrada pelas pressões sobre o governo brasileiro a fim de permitir implantação de bases aéreas e navais nas principais cidades do Nordeste - o que de fato ocorreu, com a estruturação da base naval de Recife, que foi o Quartel General da $3^{\text {a }}$ Força Tarefa da IV Frota da Marinha dos Estados Unidos.

Esta base tornou-se o centro de uma rede de bases estabelecidas no país, que abrangia desde Belém até Santa Cruz, incluindo Fernando de Noronha, Aratu, Caravelas e Vitória. Foi da IV Frota, fundeada em Recife, que partiram os aviões para missão de patrulhamento na região oceânica entre Natal e Ascensão, com o intuito de detectar e combater os submarinos do Eixo.

Encerrado o embate, os Estados Unidos reafirmaram o seu interesse de permanecer hegemônico na América Latina, tratando unilateralmente questões da região sob a orientação do Art. 52 da Carta de São Francisco.

Sendo assim, em 1947 ratificaram esta posição através do Tratado Interamericano de Assistência Reciproca (TIAR) ou Tratado do Rio de Janeiro, considerada uma nova Doutrina Monroe, ou seja, qualquer ataque a um Estado americano seria interpretado como um ataque a todos os demais. 
Em 1948, em Bogotá, a retomada da União Pan-Americana, agora sob o nome de Organização dos Estados Americanos (OEA), demonstrou cabalmente que os EUA confirmavam sua hegemonia, pois excluíam a América Latina de quaisquer ingerências da ONU (Bandeira 2010, 50).

\section{EUA: Estratégia global para América Latina}

Este esforço diplomático compreendia a execução de uma estratégia global norte-americana para a região, composta de quatro vieses: o político, o econômico, o militar e o ideológico.

A estratégia política apresenta três pontos relevantes: o primeiro ponto é manter e preservar a Doutrina Monroe e estruturar um organismo hemisférico que legitime as ações militares americanas na região; o segundo aspecto é atrair os países da região para alinharem suas políticas externas à dos Estados Unidos e apoiarem suas iniciativas nos fóruns internacionais; e, por último, a manutenção de regimes na região, sendo democráticos ou não, que garantam a liberdade de ação dos norte-americanos a fim de promoverem o que denominam de good governance.

Em relação à estratégia econômica, o objetivo principal é garantir para os produtos industriais americanos o acesso irrestrito aos mercados latino-americanos. Esta ação é sustentada pela propaganda das teorias econômicas de viés neoliberal, a saber: ideias das vantagens comparativas, de especialização agrícola e, por fim, a do livre comércio. Em contrapartida, os EUA seduziam os latino-americanos com promessas de acesso aos seus mercados através de relação bilateral ou de uma eventual integração hemisférica. Por fim, o núcleo desta estratégia é impedir quaisquer ações dos Estados latino-americanos como promotores do seu desenvolvimento econômico (Guimarães 1999, 111).

Quanto ao aspecto da estratégia militar, o foco central é a manutenção desta região como zona militar exclusiva dos Estados Unidos. O cerne desta ação encontrava-se nos seguintes pontos: 1) influência sobre o pensamento estratégico militar; ${ }^{4}$ 2) acordo de vendas de armamentos de terceira geração; e 3) acesso preferencial às matérias primas estratégicas da região.

Por último, na estratégia ideológica, o intento primordial é tornar os Estados Unidos modelo para os demais Estados, a nação líder a ser seguida. Para isso, era necessário criar em cada Estado latino-americano grupos simpatizantes dos ideais norte-americanos o que permitiria acesso às sociedades para a divulgação do american way of life. Esta ideia era posta em prática por meio do cinema, programas de televisão, divulgação da língua inglesa, além de um permanente intercâmbio de estudantes e programas de pós graduação (Guimarães 1999, 101). 


\section{América do Sul e Livre Mercado}

A importância geopolítica da América do Sul para a manutenção da hegemonia global dos EUA está baseada na sua dimensão comercial e econômica.

Como vimos na seção anterior, a estratégia econômica para atender suas necessidades produtivas, além de penetrar nos mercados latino-americanos, é garantir o acesso às fontes de matérias-primas sensíveis. Por exemplo, o petróleo na Venezuela, as minas de estanho na Bolívia e as minas de cobre no Chile. Isso implicava em manter abertas as linhas de comunicação e transporte no Atlântico Sul e no Caribe (Bandeira 2010, 51).

Para atender a estes interesses, foi lançado em 1990, pelo então Presidente George H. W. Bush, o que foi conhecido como a Iniciativa para as Américas. $\mathrm{O}$ interesse era instituir uma zona de livre comércio do Alasca até a Terra do Fogo (Bandeira 2010, 51).

Quatro anos depois, já na administração Clinton, esta concepção foi reelaborada e apresentada sob o nome de Área de Livre Comércio das Américas, cuja proposta era a integração econômica regional.

Segundo Bandeira (2010, 52):

Esta proposta de integração econômica regional encampava, porém, objetivos geopolíticos, com respeito à segurança continental, mediante o fortalecimento das instituições democráticas e combate ao narcotráfico e ao terrorismo, ameaças que substituíram a subversão e o comunismo (grifos nossos).

As pretensões com a ALCA, como também a Asia Pacific Economic Cooperation (APEC), além dos acordos como os da Rodada Uruguay, era a formação de uma rede de compromissos globais a fim de conformar o sistema econômico mundial, tendo os EUA como centro propulsor da economia global no século XXI.

Atrelado à proposta da formação da ALCA estava a aplicação de medidas neoliberais, estabelecidas pelo que ficou conhecido como Consenso de Washington. ${ }^{5}$ Estas medidas preconizavam a privatização das empresas estatais, desregulamentação da economia e liberalização unilateral do comércio exterior.

Segundo Bandeira (2010, 53):

A intenção era de abrir o mercado sul-americano para as corporações transnacionais, investidores e banqueiros, que teriam grande facilidade de movimentar capitais, bens, lucros e tecnologias sem que os governos da região pudessem criar obstáculos (grifos nossos). 
Com o fracasso das negociações para a implementação da ALCA, os EUA alteraram o rumo das negociações buscando firmar acordos de livre comércio com os países da América do Sul, América Central e Caribe. Desta forma, implementaram o Central America Free Trade Agreement (CFTA), com os países da América Central; da mesma forma com o Andean Trade Promotion and Drug Erradication Act (ATPDEA), com Peru, Colômbia, Bolívia e Equador.

\section{Colômbia: Pivot Country}

Dos quatro países andinos, a Colômbia tem um papel especial para os Estados Unidos: é um Pivot Country.

Esta designação é por conta das características geográficas do seu território. Tendo o seu litoral voltado para o Pacífico e o Caribe, é ao mesmo tempo um enclave na região noroeste do Brasil, na altura da Cabeça do Cachorro. ${ }^{6}$ Estes aspectos conferem um papel geopolítico e estratégico muito importante para os EUA, pois atua como um aríete contra o flanco da América do Sul, particularmente o Brasil.

Além destes aspectos geográficos e geopolíticos, a Colômbia é o terceiro principal fornecedor de petróleo para os norte-americanos. Das $18 \mathrm{em}-$ presas petrolíferas estabelecidas no país, 11 são firmas norte-americanas que investem na exploração de $1 / 3$ do país. Para aumentar a exportação é necessário participar com aportes financeiro em outro terço do país. Porém isto não ocorre, pois esta região é controlada pelas Forças Armadas Revolucionárias da Colômbia (FARC) e pelo Exército de Libertação Nacional (ELN). ${ }^{7}$

Dos cinco oleodutos existentes no país, o principal está no campo de Caño Limon, em Arauca, para o porto de Conveñas, no Caribe, e que estão permanentemente sofrendo ataques das tropas das FARC e da ELN.

Segundo Bandeira (2010, 58):

Não foi outra a razão pela qual o Presidente Bill Clinton, em 2000, lançou o Plano Colômbia, prevendo investimentos de US\$ 6 bilhões, dos quais os Estados Unidos participariam com US\$ 1,3 bilhão para a compra de helicópteros e outros armamentos.

Esta é uma das razões da ampla presença militar norte-americana na América do Sul. Ela na realidade é um desdobramento da rede logística das Forças Armadas, que abrange bases militares ou núcleos de apoio sob o comando do U.S. Southern Command (South Com) (The U.S. Southern Command 2009). 
A área de sua responsabilidade corresponde a América Central, Caribe e América do Sul, cujas bases estão posicionadas em Guantánamo (Cuba), Soto Cano (Honduras), Aruba, Curaçao (Antilhas Holandesas), Comalapa (El Salvador), Colômbia e Peru. Nestes dois últimos, estão instalados 17 centros e núcleos de apoio para operações militares (Costa 2009, 19).

A despeito do fechamento da base militar em Manta, no Equador, devido à denúncia do contrato feito pelo ex-Presidente Rafael Correa, o U.S. Southern Command a transferiu para a base aérea de Palanquero, em Puerto Salgar, a aproximadamente $190 \mathrm{~km}$ de Bogotá. Com o acordo (Defense Cooperation Agreement - DCA) franqueou-se às Forças Armadas americanas as seguintes posições : 1) Três bases aéreas localizadas em Palanquero, Apiay, aqui na região amazônica próxima à fronteira com o Brasil, denominada Cabeça de Cachorro; 2) duas bases do Exército em Malambo; e 3) duas bases navais em Cartagena e Barranquilla. (Bandeira 2010,61).

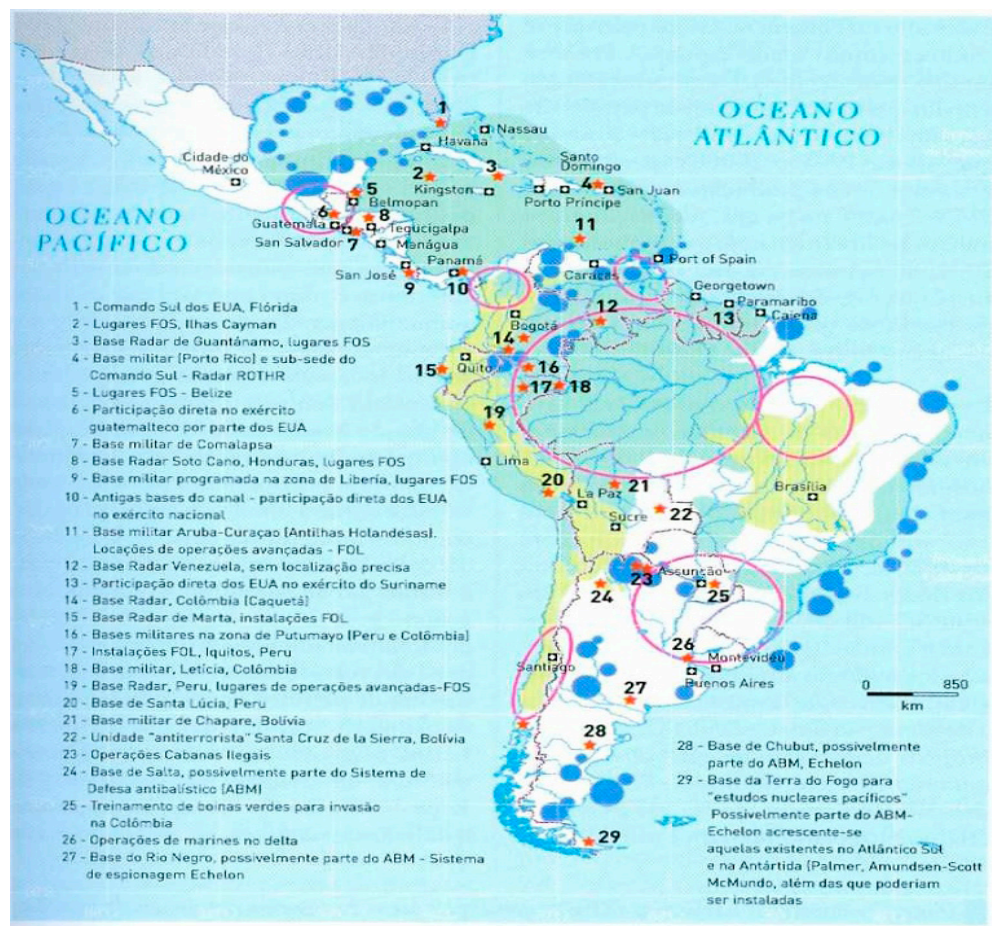

Mapa 6 - Bases Militares dos EUA na América Latina.

Fonte: Gandásegui (2015). 
O papel dos Estados Unidos é frustrar o processo de integração sul-americano liderado pelo Brasil. Para isso, investem pesadamente no Exército colombiano, tornando-se o mais bem equipado da região. Segundo Bandeira (2010,62):

Com população de 44 milhões de habitantes, a Colômbia possui um contingente militar de cerca de 208.600 efetivos, enquanto o Brasil, com 8,5 milhões de quilômetros quadrados e mais de 190 milhões de habitantes, tem um contingente de somente 287.870, e a Argentina, com 40 milhões de habitantes e um território de 2,7 milhões de quilômetros quadrados, tem um efetivo de apenas 71.655. A Colômbia, com PIB de US $\$ 320,4$ bilhões (2007 est.) [ [...] destina 3,8\% aos gastos militares, enquanto o Brasil, cujo o PIB é de US $\$ 1,838$ trilhões (2007 est) gasta apenas 1,5\% a Argentina, com um PIB de US $\$ 523,7$ bilhões (2007 est) gasta apenas $1,1 \%$ (grifos nossos).

O estacionamento de tropas não somente na Colômbia, como também no Peru, permite uma enorme vantagem estratégica para intervir militarmente em qualquer país da América do Sul a fim de defender os seus interesses e ocupar as nascentes do rio Amazonas.

Ao fim e ao cabo, a presença militar norte-americana na região é uma clara ameaça à segurança do Brasil.

Finalizando, os quase cem anos da publicação dos Aspectos Geográficos Sul-Americanos propiciam o distanciamento necessário para fazer um ajuste de contas com o fundador do campo da Geopolítica do Brasil.

Procurou-se aqui testar o valor explicativo de sua obra no contexto do ordenamento mundial do século XXI.

\section{CONSIDERAÇÕES FINAIS}

Como comentamos anteriormente, este trabalho teve o intuito de realizar uma reflexão sobre a obra do Capitão Mário Travassos, intitulada Aspectos Geográficos Sul-Americanos, publicada em 1931, a qual foi reeditado em 1947 com o título de Projeção Continental. O primeiro foi prefaciado por Pandiá Calógeras e o segundo, por Gilberto Freyre.

Segundo Ronald de Carvalho, esta obra lançou os fundamentos da Geopolítica do Brasil para a primeira metade do século XX, e suas análises e formulações políticas dominaram a mente de intelectuais e dos Oficiais das Forças Armadas até a década de 1950.

Suas ideias, podemos afirmar, representam o destino manifesto brasileiro, que se coadunava com os propósitos políticos de fortalecimento do Estado brasileiro oriundos da Revolução de 1930. 
Com estes dados em mãos, o nosso interesse foi cotejar as ideias do autor com os cenários geopolíticos atuais, no que concerne à Amazônia e principalmente à influência dos Estados Unidos na região.

Com os resultados a que chegamos podemos afirmar que as percepções de Travassos continuam relevantes para explicar as complexas realidades emergidas no século XXI.

Sustentamos este argumento demonstrando os paralelismos que existem entre os diagnósticos travassianos na década de 30, que detectaram as infiltrações dos EUA na região e as suas ações no momento atual.

Naquele momento, o autor identificou que se encontrava no Canal do Panamá e no Mar das Antilhas a origem da projeção dos Estados Unidos para a América do Sul, que exercia pressões na região noroeste, onde encontramos Equador, Colômbia e Venezuela.

Esta região foi denominada por Travassos como sendo a segunda instabilidade geográfica, por conta das suas vulnerabilidades, às infiltrações dos Estados Unidos. Esta constatação advinha da visão fisiográfica da região, que demonstrava que as bacias do Orinoco e do Madalena, localizadas respectivamente na Venezuela e na Colômbia, eram os portais de entrada dos interesses industriais dos norte-americanos, que desaguavam no vale do Amazonas. O objetivo desta penetração estava em ter acesso ao petróleo da Colômbia e da Venezuela, como também à borracha na região da Amazônia brasileira.

$\mathrm{O}$ autor chamou a atenção de que estes avanços obrigaram o Equador e a Bolívia a estabelecerem uma legislação que ratificasse a nacionalização do petróleo.

As análises de Travassos realizadas na década de 30 sobre as influências norte-americanas na America do Sul são corroboradas pela realidade atual. Esta interpretação aparece com maior força quando verificamos que a estratégia global estadunidense para a região tem como alvo preferencial um Pivot Country: a Colômbia.

Além de ser um dos principais exportadores de petróleo para os EUA, está localizada na região noroeste do continente sul, no espaço territorial que foi interpretado por Travassos como um dos signos de inquietação política por possuir um dos portais de entrada para os interesses econômicos norte-americanos. Outro ponto preocupante é a militarização do país apoiada pelo Pentágono, o que constitui uma ameaça à segurança do Brasil.

Em síntese, a obra de Travassos é considerada um clássico, porque conseguiu antecipar a paisagem geoestratégica na América do Sul na realidade do século XXI. Podemos interpretá-la como um modelo paradigmático da Geopolítica do Brasil, pois foi capaz de ordenar a realidade e sobre ela tecer generalizações; compreender as relações causais; antecipar e predizer 
desdobramentos; distinguir o que é importante do que não é; e, por último, apontar caminhos que teríamos de tomar para alcançar os nossos objetivos.

Outro aspecto relevante em nosso entendimento é o retorno, no Brasil, da discussão da Geopolítica na Academia. Entendemos a importância de criarmos uma massa crítica que seja exposta às ideias de homens que tiveram a tarefa de pensar o Brasil, da mesma maneira que Gilberto Freyre, Werneck Sodré e Celso Furtado.

\section{REFERÊNCIAS}

Anselmo, Rita e Vinícius Teixeira. 2010. "Integração e Conflitos na Região Amazônica”. Revista Geopolítica, 2 (1): 57-76.

Alsina Jr., João P. 2009. "O Poder militar como instrumento da política externa brasileira contemporânea”. Revista Brasileira de Política Internacional. 173-191.

Bandeira, Luís A. Moniz. 2010. Geopolítica e Politica Exterior: Estados Unidos, Brasil e América do Sul. Brasília: Fundação Alexandre Gusmão.

Bruckmann, Monica. 2011. "Recursos Naturais e Geopolítica da Integração Sul Americana” In: Viana, André; Barros, Pedro; Calixtre, André (Org.) Governança Global e Integração da América do Sul. Brasília: IPEA.

Calógeras, Pandiá. 2001. Dicionário Histórico Biográfico Brasileiro pós 1930. 2. ed. Rio de Janeiro: FGV. Disponível em: <http://cpdoc.fgv.br/producao/dossies/ AEraVargas 1/biografias/pandia_calogeras>. Acesso em: 09 out. 2009.

Centro de Estudo em Políticas e Estratégias Nacionais General Meira Mattos. 2000. A Geopolítica Brasileira - predecessores geopolíticos. Artigos para Escola Superior de Guerra, 9. Disponível em: <http://www.cepen.org/pdfs/art07.pdf>. Acesso em: 09 out. 2017.

Central Intelligence Agency. Disponível em: : <https://www.cia.gov/library/ publications/resources/cia-maps-publications/map-downloads/colombia_physiography.jpg/image.jpg>. Acesso em: 13 jun. 2017.

Costa, Wanderley M. 2009. "O Brasil e a América do Sul: cenários geopolíticos e os desafios da integração”. Confins. Reveu française-brésilienne de géographie. Disponível em: <http://confins.revues.org/6107>. Acesso em: 07 set. 2011.

Couto e Silva, Golbery. 1981. Planejamento Estratégico. Brasília: UnB.

Gandásegui, Marco. 2015. "América Latina y EEUU: una relación asimétrica". Disponível em: <https://puntodevistaypropuesta.wordpress.com/2015/04/11/ america-latina-y-eeuu-una-relacion-asimetrica/>. Acesso em: 13 set. 2017. 
Guimarães, Samuel Pinheiro. 1999. Quinhentos anos de periferia. Porto Alegre: UFRGS.

Mackinder, Halford. 1904. “The Geographical Pivot of History”. The Geographical Journal, XXIII (4), april. London: Read at The Geographical Society.

Mattos, Meira. 2002. Geopolítica e Modernidade: Geopolítica brasileira. Rio de Janeiro: Bibliex.

Medeiros Filho, Oscar. 1998. "Conselho de Defesa Sul-americano". In: II Encontro Nacional da Associação de Estudo de Defesa. Universidade Federal Fluminense, julho.

Mello, Leonel I. A. 1997. A Geopolítica do Brasil e a Bacia do Prata. São Paulo: Hucitec.

Miyamoto, Shiguenoli. 1981. Os Estudos Geopolíticos no Brasil: Uma contribuição para sua avaliação. São Paulo: Perspectiva.

Neves, André L. Varella. 2015. "A Geopolítica dos Estados Unidos no Século XXI: As implicações para a política de defesa do Brasil" In: Gheller, Gilberto, Gonzales, Selma, Melo, Laerte (Org.). Amazônia e Atlântico Sul: desafios e perspectivas para a defesa do Brasil. Brasília: IPEA.

Oliveira, Eliézer. R. 2009. “A Estratégia Nacional de Defesa e a Reorganização e Transformações das Forças Armadas”. Interesse Nacional. Abril/Junho. Disponível em: <http://interessenacional.uol.com.br/artigos.asp?filtro=tema\&tema $=1>$. Acesso em: 01 dez. 2011.

Oliveira, Marcos A. G. 2011. Comparando a Defesa Sul-Americana. Recife: UFPE.

Padula, Raphael. 2004. Infraestrutura, Geopolítica e desenvolvimento na integração sul-americana - uma visão crítica à IIRSA. Laboratório de Estudos da América Latina (LEAL). Disponível em: <http://leal-ufrj.blogspot.com. br/2011/04/artigo-infraestrutura-geopolitica-e.html>. Acesso em: 17 abr. 2012.

Rippel, Márcio P. 2004. O Plano Colômbia como instrumento da política norte-americana e suas consequências. Rio de Janeiro: Escola de Guerra Naval.

Spykman, Nicholas. 1942. America's Strategy in world politics: The Unites States and the balance of power. New York: Harcout, Brace and Company.

The U.S. Southern Command.2009. The Area of Responsibility. Disponível em: <http://www.southcom.mil/aboutus/Pages/Area-of-Responsibility.aspx>. Acesso em: 14 mar. 2010. 
RBED, v. 5, no 1 , jan./jun. 2018

Tosta, Otávio. 1981. Teorias Geopolíticas. Rio de Janeiro: Bibliex.

Travassos, Mário. 1942. Introdução à Geografia das Comunicações Brasileira. Rio de Janeiro: Jose Olympio.

Travassos, Mário. 1947. Projeção Continental do Brasil. São Paulo: Nacional. 


\section{NOTAS}

1. O autor baseia-se na experiência histórica do Império Alemão, que aspirava às saídas ao Mar Báltico, na época de Frederico Guilherme, O Grande Eleitor (1640-1688), e de Frederico, O Grande (1740-1786), que buscou saídas para dois mares diferentes, o Báltico e o Mar do Norte, e tentou buscar alianças com Estados que permitissem acessar um mar fundamentalmente diferente daqueles dois, o Mediterrâneo. Outro exemplo importante é o comportamento da Rússia que, impedida de navegar no Oceano Ártico, sempre almejou saídas livres no Pacífico, nas proximidades do Mar da Noruega e no Oceano Índico. Sobre as atuações políticas dos Estados ao domínio de bacias hidrográficas, o autor cita a preocupação da Rússia em estender sua influência ao alto do curso do Rio Amur e incorporar sob seu domínio os seus afluentes. Ainda na rede hidrográfica da Ásia, o autor aponta a influência britânica ao instalar-se na desembocadura do rio mais extenso da Ásia, o Iang-Tse-Kiang.

2. Divortium aquarium: Expressão latina utilizada por Mário Travassos para designar a divisão ou dispersão de águas que se processa no centro do continente, mais precisamente na região do altiplano boliviano, entre as duas grandes bacias hidrográficas da América do Sul: a Amazônica e a Platina.

3. Nudos: Zona de menor resistência cuja plataforma serve de ponto de travessia da gigantesca barreira formada pela Cordilheira dos Andes.

4. Esta influência ocorreria através de programas de formação de Oficiais das Forças Armadas.

5. Consenso de Washington: formado pelo Fundo Monetário Internacional, Banco Mundial e o Departamento do Tesouro dos Estados Unidos.

6. Cabeça do Cachorro: região cujo nome é dado exatamente pelo seu contorno no mapa brasileiro, ocupa 200 mil quilômetros quadrados, área maior do que muitos países europeus. Faz parte do município de São Gabriel da Cachoeira, o terceiro maior do País em extensão territorial. Constituída à margem esquerda do Rio Negro, está a 1.146 quilômetros de Manaus por via fluvial, distância maior do que São Paulo a Porto Alegre.

7. Em 2016, o ex-Presidente da Colômbia, Juan Manuel Santos, e o líder rebelde marxista das Forças Armadas Revolucionárias da Colômbia (Farc), Rodrigo Londoño, assinaram um acordo de paz

8. South Com: dentre suas tarefas incluem-se o combate ao narcotráfico, o relacionamento com as Forças Armadas dos diversos países, o controle e a não-proliferação de armas, operações antiterrorismo, a assistência humanitária e operações de busca e salvamento. 


\section{A GEOPOLÍTICA DA AMAZÔNIA NO SÉCULO XXI: \\ O PENSAMENTO DE MÁRIO TRAVASSOS REVISITADO}

\section{RESUMO}

O objeto deste artigo é a tese do Capitão Mário Travassos apresentada na obra intitulada Aspectos Geográficos Sul-Americanos, de 1931. O objetivo foi submetê-la ao crivo das mudanças da política internacional na América do Sul no século XXI, focando na presença dos EUA na região. Concluímos que os seus prognósticos permanecem atuais.

Palavras-chave: Mário Travassos; Amazônia; Estados Unidos da América; Países Andinos.

\section{ABSTRACT}

The purpose of this article is Captain Mario Travassos' thesis presented in the work titled South American Geographical Aspects of 1931. The goal was to submit it to the screen of international policy changes in South America in the $21^{\text {st }}$ century, focusing on the US presence in the region. We conclude that its prognoses remain current.

Keywords: Mario Travassos; Amazonia; The United States of America; Andeans Countries. 